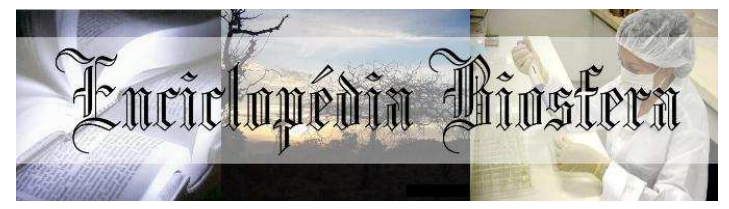

\title{
EFEITO DA SALINIDADE DA ÁGUA DE IRRIGAÇÃO NA PRODUÇÃO DE ALFACE CRESPA
}

\author{
Alismário Leite da Silva', Marilza Neves do Nascimento ${ }^{2}$, Tamara Torres Tanan ${ }^{3}$, \\ Uasley Caldas de Oliveira ${ }^{4}$, Janderson do Carmo Lima ${ }^{5}$, \\ ${ }^{1}$ Graduando em Agronomia, Universidade Estadual de Feira de Santana (UEFS), \\ Feira de Santana, Brasil . (alismarioagronomo@hotmail.com) \\ ${ }^{2}$ Professora Doutora do Curso de Agronomia, Universidade Estadual de Feira de \\ Santana (UEFS), Feira de Santana, Brasil \\ ${ }^{3}$ Doutoranda em Recursos Genéticos Vegetais pela Universidade Estadual de Feira \\ de Santana (UEFS), Feira de Santana, Brasil \\ ${ }^{4}$ Mestrando em Solos e Qualidade de Ecossistemas, Universidade Federal do \\ Recôncavo Baiano (UFRB), Cruz das Almas, Brasil \\ ${ }^{5}$ Doutorando em Recursos Genéticos Vegetais pela Universidade Estadual de Feira \\ de Santana (UEFS), Feira de Santana, Brasil
}

Recebido em: 02/10/2017 - Aprovado em: 21/11/2017 - Publicado em: 05/12/2017 DOI: 10.18677/EnciBio_2017B28

\begin{abstract}
RESUMO
Objetivou-se nesse trabalho avaliar o desenvolvimento da Alface Crespa em diferentes níveis de salinidade em casa de vegetação. O ensaio foi desenvolvido em ambiente protegido do Horto Florestal da Universidade Estadual de Feira de Santana, BA, com delineamento experimental inteiramente casualizado, com seis repetições. As plantas de alface foram submetidas a cinco níveis de concentrações salinas $\left(0,2,4,8\right.$ e $\left.16 \mathrm{dSm}^{-1}\right)$ e avaliadas quanto a altura da planta (ALT), diâmetro do caule (DCA), número de folhas (NF), massa seca das folhas (MSF), massa seca do caule (MSC), massa seca da raiz (MSR), massa seca total (MST) e área foliar $(\mathrm{AF})$, que apresentaram resposta linear decrescente às doses salinas, com reduções mais acentuadas em $16 \mathrm{dSm}^{-1}$. As plantas de alface são sensíveis a salinidade na água de irrigação, com redução do crescimento e acúmulo de fitomassa à medida que aumenta os níveis salinos.
\end{abstract}

PALAVRAS-CHAVE: Crescimento, Estresse salino, Qualidade da água.

\section{EFFECT OF IRRIGATION WATER SALINITY ON LOOSELEAF LETTUCE PRODUCTION IN GREENHOUSE}

\begin{abstract}
The objective of this work was to evaluate the development of looseleaf lettuce in different levels of salinity in greenhouse. The experiment was conducted under greenhouse conditions of the Horto Florestal of the State University of Feira de Santana, State of Bahia, and was installed in a completely randomized experimental design with six replicates. The lettuce plants were submitted to five levels of saline concentrations $\left(0,2,4,8\right.$ and $\left.16 \mathrm{dSm}^{-1}\right)$, and plant height, stem diameter, number of leaves, leaf dry weight, stem dry weight, root dry weight, total dry weight and leaf
\end{abstract}


area were evaluated. The variables showed a decreasing linear response to the saline doses, with the greatest reductions by $16 \mathrm{dSm}-1$. Lettuce plants are sensitive to salinity in irrigation water, with the growth and biomass accumulation as salt levels increase.

KEYWORDS: Growth, Saline stress, Water quality.

\section{INTRODUÇÃO}

Dentre as hortaliças folhosas, a alface (Lactuca sativa L.) é a que apresenta maior produção e consumo no país. Caracteriza-se por seu porte herbáceo e caule diminuto, aos quais suas folhas são presas. Pertencente à família Asteraceae e subfamília Cichorioideae, a alface tem suas folhas consumidas na forma "in natura", assegurando, portanto, a manutenção das suas propriedades nutritivas. Apresenta teores de vitamina $A$ e $B$ e sais minerais, como cálcio e ferro. Tem seu valor calórico considerado baixo e devido a isso é comumente indicada em dietas que fazem uso de baixos índices calóricos (SCHERER et al., 2016). Além disso, é apontada como uma hortaliça que expressa funções tranquilizantes (FONSECA et al., 2013).

A cultura tem grande relevância econômica no mercado brasileiro, alto valor nutricional e social, visto que proporciona não só fonte de subsistência, mas sim aumento de renda a muitos produtores, sendo cultivada em sua maior parte por agricultores familiares (CARVALHO; SABBAG, 2015). Possui destaque na preferência dos olericultores devido à facilidade de cultivo e a grande aceitação na mesa dos consumidores (SCHERER et al., 2016).

É uma hortaliça que pode ser cultivada durante todo o ano, entretanto, durante a primavera e verão tem sua produção reduzida (FONSECA et al., 2013), sendo afetada pelas alterações climáticas como a densidade pluviométrica e a elevação de temperatura (HIRATA et al., 2014). As práticas agrícolas realizadas também influenciam na produtividade, como por exemplo, a quantidade e a qualidade da água usada na irrigação. O uso de águas com alta concentração de sais solúveis leva a salinização do solo, prejudicando o crescimento e desenvolvimento vegetal (SANTANA et al., 2003).

Nawaz et al. (2014) reportam o sério comprometimento das plantas aos estresses simultâneos, sendo o crescimento severamente prejudicado na presença do fator salinidade. Com isso, formas de convivência vêm sendo estudadas por muito tempo, e uma das mais utilizadas é o cultivo de espécies tolerantes, sendo essa uma estratégia recomendada por profissionais para a reabilitação de solos degradados pelo efeito da salinização (PENELLA et al., 2016).

Segundo Kaiser et al. (2016) a salinidade tem grande impacto na produção agrícola em todo mundo, dificultando, mais precisamente, nas regiões áridas e semiáridas, tendo como principais fatores os longos períodos de estiagem, as altas taxas de evaporação e a grande ocorrência de solos rasos. Por serem regiões onde as águas de superfície são escassas, as águas subterrâneas se tornam essenciais para a realização da produção, além de garantir as necessidades de várias comunidades. Atualmente, em torno de $70 \%$ da água proveniente do solo é utilizada na agricultura (GHODRATI; GHAZARYAN, 2013).

Desta forma, se fazem necessárias pesquisas visando práticas de manejo dessas águas salobras que venham a possibilitar o seu uso na agricultura irrigada, com maior retorno econômico e buscando reduzir cada vez mais os impactos ambientais pelo uso inadequado dessas águas (OLIVEIRA et al., 2011a). Diante do exposto, objetivou-se com este trabalho avaliar o crescimento e o acúmulo de 
biomassa da Alface Crespa cultivada em diferentes níveis de salinidade em casa de vegetação.

\section{MATERIAL E MÉTODOS}

O experimento foi conduzido no período de junho a julho de 2017, na Unidade Experimental Horto Florestal pertencente à Universidade Estadual de Feira de Santana (UEFS), localizado no município de Feira de Santana-BA, (12¹6'00"S, 3858'00"O, 257 metros de altitude). O clima da região é de seco a subúmido e semiárido, com o período chuvoso compreendido entre os meses de abril e junho. A pluviosidade anual média é de $867 \mathrm{~mm}$, com máxima de $1595 \mathrm{~mm}$ e mínima de 444 $\mathrm{mm}$.

Para a produção de mudas da alface crespa, foram utilizadas sementes da marca Horticeres Sementes, da safra de 2015, com $90 \%$ de germinação e $99 \%$ de pureza. A semeadura ocorreu em bandejas de poliestireno expandido utilizando substrato comercial Techns Vivato®. Quando as plantas apresentavam aproximadamente $10 \mathrm{~cm}$ foi realizado o transplante para vasos com capacidade de $3 \mathrm{dm}^{3}$, preenchidos com solo coletado na Unidade Experimental Horto Florestal a profundidade de 0 a $20 \mathrm{~cm}$. Os recipientes foram dispostos em bancadas em ambiente protegido. A adubação foi realizada com base na análise química do solo utilizado (Tabela 1) e no Manual de Adubação e Calagem para o Estado da Bahia (CEFS, 1989).

TABELA 1 - Caracterização química do solo da Unidade Experimental Horto Florestal na profundidade $0-20 \mathrm{~cm}$, Feira de Santana-Ba, 2017.

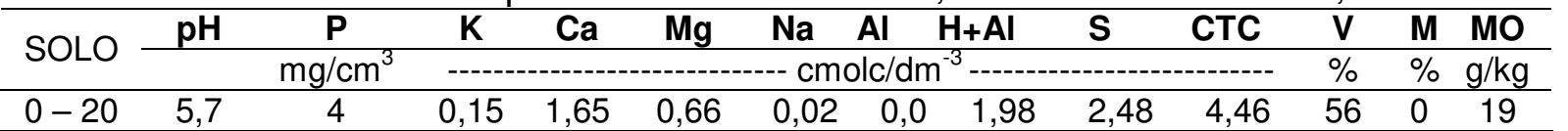

H+Al - acidez potencial, SB - soma, CTC - capacidade de troca catiônica, MO - matéria orgânica, V\% saturação por bases.

Os tratamentos consistiram em cinco níveis de salinidade da água de irrigação $\left(0,2,4,8\right.$ e $\left.16 \mathrm{dSm}^{-1}\right)$ com seis repetições (Tabela 2). As soluções foram preparadas com cloreto de sódio $(\mathrm{NaCl})$ de acordo com Richards (1980), considerando solos salinos aqueles com a condutividade elétrica $(E C e)>4$. Quando $4<\mathrm{ECe}<8$, os solos são considerados moderadamente salinos, e quando ECe $>16$, severamente salino. As medições da condutividade elétrica da água de irrigação foram realizadas utilizando condutivímetro de bancada.

TABELA 2. Conversão da quantidade de Cloreto de Sódio em condutividade elétrica dos tratamentos utilizados para o cultivo da alface.

\begin{tabular}{cccc}
\hline TRATAMENTOS & $\mathbf{N a C l}\left(\mathbf{g} \cdot \mathbf{~ L}^{-1}\right)$ & ECe $\left(\mathbf{d S} \cdot \mathbf{m}^{-1}\right)$ & MOLARIDADE \\
\hline 1 & 0,0 & 0 & 0 \\
2 & 1,0 & 2 & 17 \\
3 & 2,0 & 4 & 34 \\
4 & 4,4 & 8 & 55 \\
5 & 9,0 & 16 & 75
\end{tabular}

Fonte: RICHARDS (1980). 
Após 25 dias do transplante (DAT) foram avaliadas as seguintes variáveis: altura da planta (ALT), utilizando régua graduada; diâmetro do caule (DCA) através de paquímetro digital; número de folhas (NF) determinado pela contagem das folhas verdes maiores do que $3,0 \mathrm{~cm}$ de comprimento, desprezando-se as amareladas e/ou secas, partindo-se das folhas basais até a última folha aberta; massa seca das folhas (MSF); massa seca do caule (MSC), massa seca da raiz (MSR) e massa seca Total (MSTO), obtidas após secagem do material vegetal em estufa com circulação forçada de ar a $70{ }^{\circ} \mathrm{C}$ até atingir peso constante, sendo expresso em gramas; e área foliar (AF), utilizando-se o integrador de área foliar modelo LI-3100 da Licor.

Os dados obtidos foram submetidos à análise de variância e de regressão, sendo ajustadas as equações das características avaliadas como variáveis dependentes dos níveis de salinidade. As análises estatísticas foram realizadas utilizando o software estatístico Sisvar 4.1 ® (FERREIRA, 2008).

\section{RESULTADOS E DISCUSSÃO}

$O$ aumento da salinidade teve efeito negativo sobre a altura das plantas e 0 diâmetro do caule (Figura 1). Para a altura das plantas (Figura 1a) observaram-se menores valores quando as plantas de alface foram submetidas a $16 \mathrm{dSm}^{-1}$ da água de irrigação $(13,4 \mathrm{~cm})$, correspondendo a uma redução de $54,65 \%$ em relação ao controle $(29,55 \mathrm{~cm})$. O diâmetro do caule apresentou comportamento similar, reduzindo linearmente com o aumento da salinidade (Figura $1 b$ ), havendo uma redução de $80,5 \%$ nas plantas a $16 \mathrm{dSm}^{-1}(2,62 \mathrm{~mm})$ quando comparadas ao tratamento testemunha $(13,40 \mathrm{~mm})$.
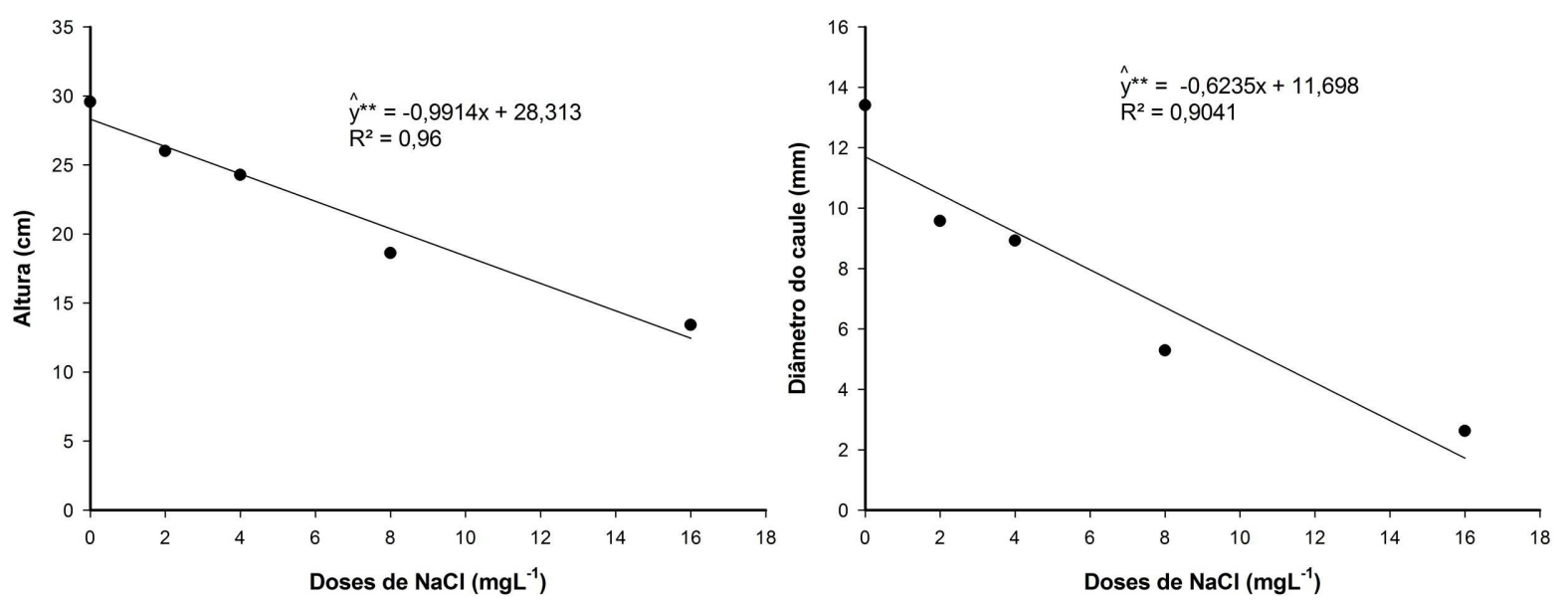

** significativo - análise de variância $(p>0,01)$.

FIGURA 1. Altura da planta (A) e diâmetro do caule (B) de Alface crespa em diferentes níveis salinos da água de irrigação. Horto Florestal/UEFS, Feira de Santana-BA, 2017.

Essa considerável redução pode ser explicada pela forma de adaptação das plantas a condições adversas, em que as plantas promovem a diminuição do gasto de energia e por consequência disso, como estrategia adaptativa, as plantas tem seu crescimento influenciado negativamente (LIU;JIANG, 2015).

Lima et al. (2015) observaram também redução linear pela salinidade, apresentando decréscimo na altura da planta em torno de $27,50 \%$ na cultura da berinjela, já Oliveira et al. (2013) verificaram que salinidade da água utilizada na irrigação afetou de maneira significativa a altura das plantas aos 40 e 60 dias após a 
semeadura de feijão-caupi. Para a variável diâmetro do caule, Fonseca et al. (2015) encontraram diferença significativa entre as cultivares de alface Pira roxa e gloriosa em dois níveis de concentrações salinas.

Mediante o aumento dos níveis salinos da água de irrigação pôde-se observar que houve redução no número de folhas, onde percebeu-se uma redução de $56 \%$ para as plantas cultivadas a maior concentração salina (Figura 2a). A redução do número de folhas em condições de estresse salino é uma das possibilidades que as plantas buscam para manter a absorção de água, como consequência de alterações morfológicas e anatômicas, refletindo-se na redução da transpiração (TESTER; DAVENPORT, 2003).
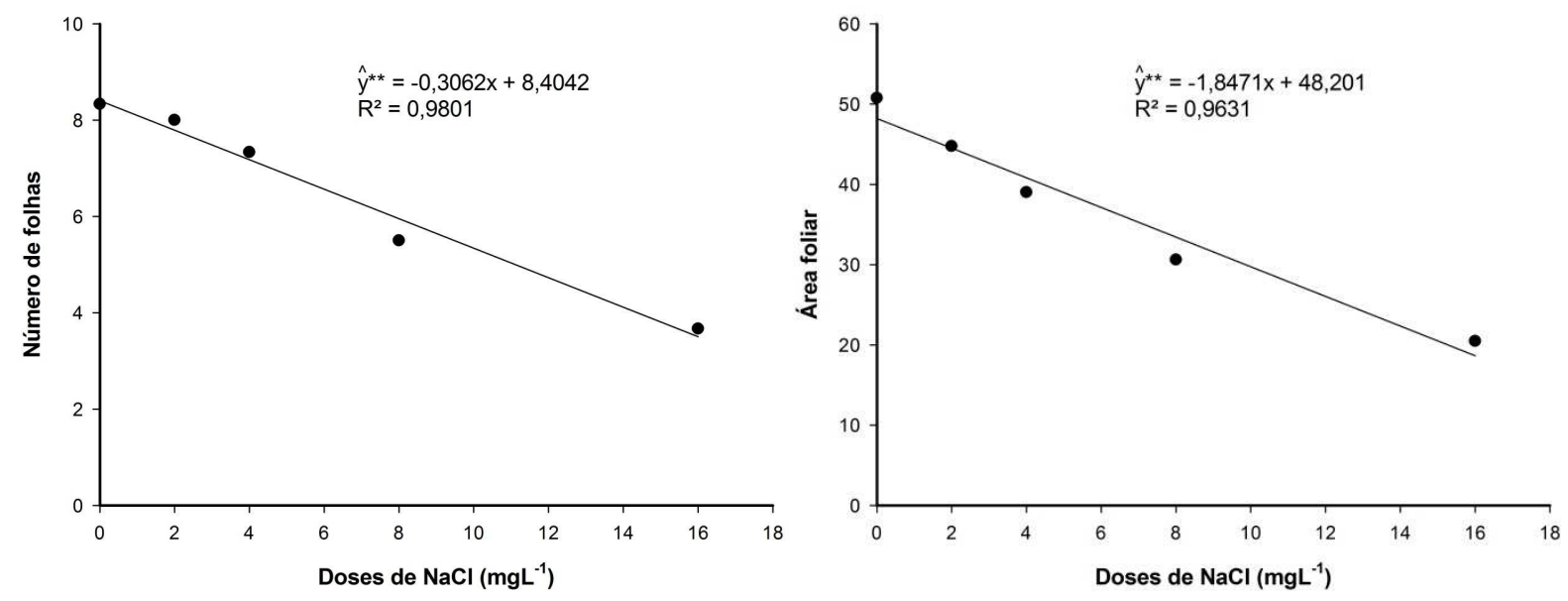

** significativo - análise de variância $(p>0,01)$.

FIGURA 2. Número de folhas (A) e Área foliar (B) de Alface crespa em diferentes níveis salinos. Horto Florestal/UEFS, Feira de Santana-BA, 2017.

Guedes Filho et al. (2013) verificaram que, com o aumento da salinidade da água de irrigação houve maior redução no número de folhas das plantas de girassol. Tambem Oliveira et al. (2014) trabalhando com maxixeiro, observou redução de $32,3 \%$ com o grau de salinidade de $5,0 \mathrm{dSm}^{-1}$. Além disso, trabalhos realizados com outras culturas também expressaram o efeito da salinidade sobre o número de folhas à medida que foi elevada a concentração salina da água de irrigação, Oliveira et al. (2007) constatou redução no número de folhas na cultura do milho-pipoca a medida que foi elevada a concentração de sais.

Foi verificado maior área foliar, $50,74 \mathrm{~cm}^{2}$, para o tratamento controle e menor valor, $20,47 \mathrm{~cm}^{2}$, para o tratamento com $16 \mathrm{dSm}^{-1}$ da água de irrigação, havendo assim um decréscimo significativo na área foliar de $59,66 \%$ (Figura $2 b$ ). A área foliar tem grande relevância para a Alface, pois é uma variável de crescimento indicativa da produtividade, visto que, o processo fotossintético depende da interceptação da energia luminosa e sua conversão em energia química, sendo este um processo que ocorre diretamente na folha (TAIZ; ZEIGER, 2009).

A redução da área foliar é um importante mecanismo adaptativo de plantas cultivadas em condições de excesso de sais e estresse hídrico, visto que, sob tais condições é interessante a redução na transpiração e, consequentemente, diminuição do carregamento de íons $\mathrm{Na}^{+}$e $\mathrm{Cl}^{-}$no xilema e concomitante conservação de água nos tecidos das plantas (TAIZ; ZEIGER, 2009). Desta forma, a 
inibição na expansão do limbo foliar é uma das características mais comuns em plantas submetidas ao estresse, sendo que em algumas culturas já é observado, como na cultura da rúcula (OLIVEIRA et al., 2012), e em outras hortaliças folhosas, como alface (DIAS et al., 2011; OLIVEIRA et al., 2011b).

Assim como as demais variáveis, a massa seca da raiz foi afetada pelo aumento da salinidade. Na dose correspondente a $16 \mathrm{dSm}^{-1}$ foi observada média de 0,0116 g planta $^{-1}$, valor $56,39 \%$ inferior ao controle, onde foi obtido em média 0,0266 g planta $^{-1}$ (Figura 3a). Esses dados corroboram com Rodrigues et al. (2015) que verificaram resposta linear decrescente com o aumento da salinidade da água de irrigação para a variável massa seca da raiz. De maneira semelhante, houve redução da massa seca do caule (Figura $3 \mathrm{~b}$ ) em função dos níveis salinos, havendo redução $87,18 \%$ da massa seca do caule do tratamento $16 \mathrm{dSm}^{-1}$ em relação ao controle.
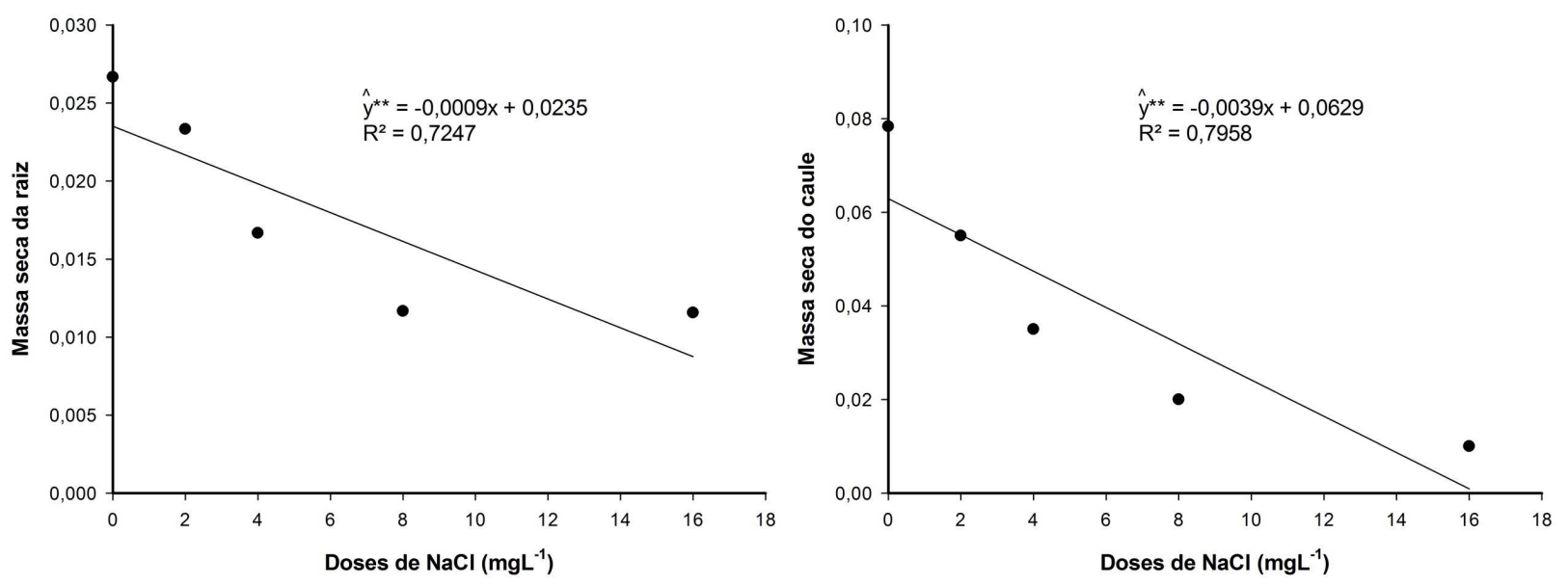

** significativo - análise de variância $(p>0,01)$.

FIGURA 3. Massa seca da raiz (A) e massa seca do caule (B) de Alface crespa em diferentes níveis salinos. Horto Florestal/UEFS, Feira de Santana-BA, 2017.

A variável massa seca das folhas demonstrou comportamento linear decrescente com o aumento da salinidade (Figura 4a), obtendo menor acúmulo de fitomassa em $16 \mathrm{dSm}^{-1}$, com média de 0,086 g.planta $^{-1}$, valor inferior em $74,71 \%$ às plantas cultivadas sem tratamento de salinidade, que apresentaram $0,34 \mathrm{~g} \mathrm{planta}^{-1}$. Alguns autores também verificaram redução na massa seca de diferentes culturas em virtude da salinidade do meio, como, por exemplo, o milho pipoca (OLIVEIRA et al., 2007), entre outras culturas de interesse agronômico. 

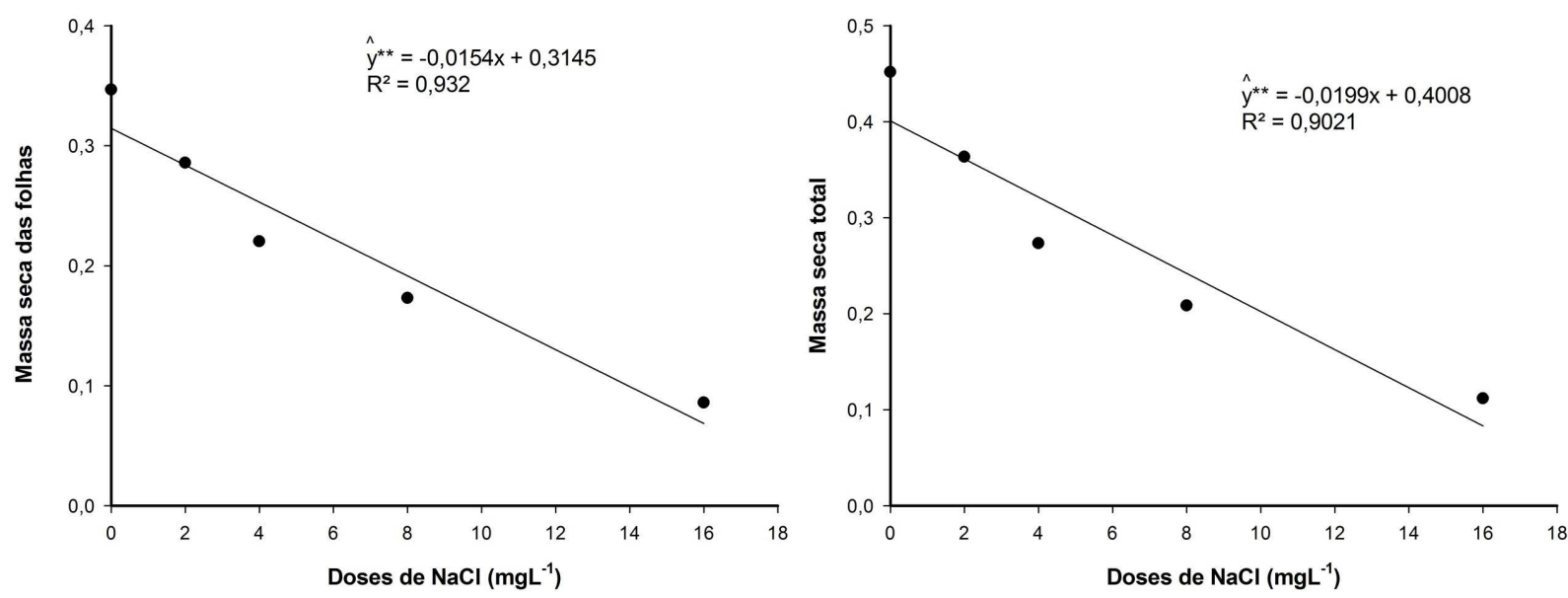

** significativo - análise de variância $(p>0,01)$; *

FIGURA 4. Massa seca das folhas (A) e massa seca total (B) de Alface crespa em diferentes níveis salinos. Horto Florestal/UEFS, Feira de Santana-BA, 2017.

A massa seca total também foi influenciada negativamente pelos níveis de salinidade empregados no experimento (Figura 4b). A variável apresentou comportamento linear, havendo redução de $75,28 \%$ da massa seca para o nível mais elevado de salinidade $16 \mathrm{dSm}^{-1}$, onde obteve média de $0,1116 \mathrm{~g}$. com relação ao tratamento controle que foi observado média de $0,4516 \mathrm{~g}$.

Sá et al. (2017) encontram redução no acumulo de fitomasssa em genótipos de citros com o aumento da salinidade da água de irrigação. Para a cultura da alface, vários autores verificaram redução significativa na massa seca em resposta à salinidade (SANTOS et al., 2010; DIAS et al., 2011; OLIVEIRA et al.,2011b). Dessa forma, resultados com baixos índices no desenvolvimento podem ser atribuídos ao aumento da concentração de sais, que atuam negativamente no processo fisiológico, reduzindo a absorção de água pelas raízes, inibindo a atividade meristemática, o alongamento celular e, em consequência, reduzindo o crescimento e o desenvolvimento das plantas (TAIZ; ZEIGER, 2009).

\section{CONCLUSÃO}

Níveis crescentes de salinidade afetam o crescimento e desenvolvimento de plantas de alface crespa, com significativa redução na emissão de folhas, área foliar, altura da planta e do acúmulo de fitomassa.

O diâmetro do caule e a fitomassa seca do caule das plantas de alface são os parâmetros mais sensíveis a salinidade.

\section{REFERÊNCIAS}

CARVALHO, J.B.; SABBAG, O.J. Análise de eficiência da produção de alface no noroeste de São Paulo. Revista Agro@mbiente On-line, v. 9, n. 2, p. 152-160, 2015. Disponível em: <http://dx.doi.org/10.18227/1982-8470ragro.v9i2.2256> DOI: 10.18227/1982-8470ragro.v9i2.2256

CEFS - COMISSÃO ESTADUAL DE FERTILIDADE DO SOLO / BA. Manual de adubação e calagem para o estado da Bahia. Salvador, CEPLAC/EMATERBA/EMBRAPA/ EPABA/ NITROFÉRTIL, 1989. 173p. 
DIAS, N. S.; JALES, A. G. O.; SOUSA NETO, O. N.; GONZAGA, M. I. S.; QUEIROZ, I. S. R.; et al. Uso de rejeito da dessalinização na solução nutritiva da alface, cultivada em fibra de coco. Revista Ceres, v.58, n.5, p.632-637, 2011. Disponível em: < http://dx.doi.org/10.1590/S0034-737X2011000500014> DOI: 10.1590/S0034737X2011000500014

FERREIRA, D. F. SISVAR: Um programa para analises e ensino de estatística. Revista Científica Symposium,v. 6, p. 36-41, 2008.

FONSECA, P. R. B.; SCHUCK, M. B; SILVA, J. A. N. Diferentes tipos de alface sob duas condutividades na hidroponia. Revista Eletrônica da Faculdade de Ciências Exatas e da Terra. v. 5, n. 7, 2015. Disponível em: <http://www.unigran.br/ciencias_exatas/conteudo/ed7/artigos/02.pdf>

FONSECA, A, S.; THOMAZINI, A.; BERTOSSI, A. P. A.; AMARAL, J. F. T. Análisede crescimento e absorção de fósforo em alface. Revista Nucleus, v.10, n.2, out. 2013. Disponível em: <http://dx.doi.org/10.3738/1982.2278.895> DOI: $10.3738 / 1982.2278 .895$

GHODRATI, M.; GHAZARYAN, S. Agriculture water supply in semi-arid zone by underground dams. European Journal of Experimental Biology, v. 33, n. 3, p. 706$711,2013$.

GUEDES FILHO, D. H.; SANTOS, J. B.; GHEYI, H. R.; CAVALCANTE, L. F.; FARIAS, H. L. Biometria do girassol em função da salinidade da água de irrigação e da adubação nitrogenada. Revista Brasileira de Agricultura Irrigada, v. 7, n. 5, p. $2772013.289, \quad$ Disponível em: <http://www.inovagri.org.br/revista/index.php/rbai/article/view/174/pdf_145> DOI: 10.7127/RBAI.V7N500174

HIRATA, A. C. S.; HIRATA, E. K.; GUIMARÃES, E.C.; RÓS, A. B.; MONQUERO, P. A. Plantio direto de alface americana sobre plantas de cobertura dessecadas ou roçadas. Revista Solos e nutrição de plantas, Bragantia, Campinas, v. 73, n. 2, p.178-183, 2014. Disponível em: < http://dx.doi.org/10.1590/brag.2014.024> DOI: 10.1590/brag.2014.024

KAISER, I. S.; MACHADO, L. C.; LOPES, J. C.; MENGARDA, L. H. G.; Efeito de liberadores de óxido nítrico na qualidade fisiológica de sementes de repolho sob salinidade. Revista Ceres, v. 63, n.1, p. 039-045, 2016. Disponível em: < http://dx.doi.org/10.1590/0034-737X201663010006> DOI: 10.1590/0034737X201663010006

LIMA, L. A.; OLIVEIRA, F. S.; ALVES, R. C.; LINHARES, P. S. F.; MEDEIROS, A. M. A.; et al. Tolerância da berinjela à salinidade da água de irrigação. Revista Agro@mbiente On-line, v. 9, n. 1, p. 27-34, janeiro-março, 2015. Disponível em: <http://dx.doi.org/10.5327/Z1982-8470201500012202> DOI: $\quad 10.5327 / Z 1982-$ 8470201500012202 
LIU, M.; JIANG, Y. Genotypic variation in growth and metabolic responses of perennial ryegrass exposed to short-term waterlogging and submergence stress. Plant Physiology and Biochemistry, v.95, p.57-64, 2015. Disponível em: <https://doi.org/10.1016/j.plaphy.2015.07.008> DOI: 10.1016/j.plaphy.2015.07.008

NAWAZ, T.; HAMEED, M.; ASHRAF, M.; AHMAD, M. S. A.; BATOOL, R.; et al. Anatomical and physiological adaptations in aquatic ecotypes of Cyperus alopecuroides Rottb. under saline and waterlogged conditions. Aquatic Botany, v.116, p.60-68, 2014. Disponível em: <https://doi.org/10.1016/j.aquabot.2014.01.001> 10.1016/j.aquabot.2014.01.001

OLIVEIRA, F. S.; PINTO, K. S. O.; BEZERRA, F. M. S.; LIMA, L. A.; CAVANCANTE, A. L. G.; et al. Tolerância do maxixeiro, cultivado em vasos, à salinidade da água de irrigação. Revista Ceres, Viçosa, v. 61, n.1, p. 147-154, jan/fev, 2014. Disponível em: < http://dx.doi.org/10.1590/S0034-737X2014000100020> DOI: 10.1590/S0034737X2014000100020

OLIVEIRA, F. A.; MEDEIROS, J. F.; OLIVEIRA, M. K. T.; SOUZA, A. A. T.; FERREIRA, J. A.; et al. Interação entre salinidade e bioestimulante na cultura do feijão caupi. Revista Brasileira de Engenharia Agrícola e Ambiental. v.17, n.5, p.465-471, 2013. Disponível em:< http://dx.doi.org/10.1590/S141543662013000500001 > DOI: 10.1590/S1415-43662013000500001

OLIVEIRA, F. A.; OLIVEIRA, M. K. T.; SOUZA NETA, M. L.; SILVA, R. T.; SOUZA, A. A. T.;et al. Desempenho de cultivares de rúcula submetidas a diferentes níveis de salinidade da água de irrigação. Agropecuária Científica no Semiárido, Pombal, v.8, n.3, p. 67-73, 2012.

OLIVEIRA, F. A.; CAMPOS, M. S.; OLIVEIRA, F. R. A.; OLIVERA, M. K. T.; MEDEIROS, J. F.; et al. Desenvolvimento e concentração de nitrogênio, fósforo e potássio no tecido foliar da berinjela em função da salinidade. Revista Brasileira de Ciências Agrárias, v. 6 , n. 1, p. 37-45, 2011a. Disponível em: <http://dx.doi.org/10.5039/agraria.v6i1a807> DOI: 10.5039/agraria.v6i1a807

OLIVEIRA, F. A.; CARRILHO, M. J. S. O.; MEDEIROS, J. F.; MARACAJÁ, P. B.; OLIVEIRA, M. K. T. Desempenho de cultivares de alface submetidas a diferentes níveis de salinidade da água de irrigação. Revista Brasileira de Engenharia Agrícola e Ambiental, v.15, n.8, p.771-777, 2011b. Disponível em: <http://dx.doi.org/10.1590/S1415-43662011000800002>ＤOI: $10.1590 / S 1415-$ 43662011000800002

OLIVEIRA, F. DE A.; MEDEIROS, J. F.; OLIVEIRA, M. K. T.; LIMA, C. J. G. S.; GALVÃO, D. C. Desenvolvimento inicial do milhopipoca 'Jade' irrigado com água de diferentes níveis de salinidade. Revista Verde de Agroecologia e Desenvolvimento Sustentável, v.2, p.45-52, 2007. Disponível em: < http://dx.doi.org/10.5039/agraria.v4i2a5 > DOI:10.5039/agraria.v4i2a5

PENELLA, C.; LANDI, M.; GUIDI, L.; NEBAUER, S. G.; PELLEGRINI, E.; et al. Salttolerant rootstock increases yield of pepper under salinity through maintenance of 
photosynthetic performance and sinks strength. Journal of Plant Physiology, v.193, p.1-11, 2016. Disponível em: <https://doi.org/10.1016/j.jplph.2016.02.007> DOI: 10.1016/j.jplph.2016.02.007

RICHARDS, L. A. Suelos salinos e sodicos. Instituto Nacional de InvestigacionesAgricolas. Mexico, 1980.171p.

RODRIGUES, R. R.; BERTOSSI, A. P. A.; GARCIA, G. O.; ALMEIDA, J. R.; SILVA. E. A.; Salinidade no desenvolvimento de cultivares de alface. Agrarian Academy, Centro Científico Conhecer - Goiânia, v.2, n.04; p. 70, 2015. Disponível em: $<$ http://dx.doi.org/10.18677/Agrarian_Academy_019> 10.18677/Agrarian_Academy_019

SÁ, F. V. S.; BRITO, M. E. B.; FIGUEIREDO, L. C.; MELO, A. S.; SILVA, L. A.; et al. Biochemical components and dry matter of lemon and mandarin hybrids under salt stress. Revista Brasileira de Engenharia Agrícola e Ambiental. v.21, n.4, p.249253, 2017. Disponível em: < http://dx.doi.org/10.1590/18071929/agriambi.v21n4p249-253> DOI: 10.1590/1807-1929/agriambi.v21n4p249-253

SANTANA, M. J. de; CARVALHO, J. A.; SILVA, E. L.; MIGUEL, D. S. Efeito da irrigação com água salina em um solo cultivado com o feijoeiro (Phaseolus vulgaris L.). Ciência e Agrotecnologia, Lavras. v.27, n.2, p.443-450, 2003. Disponível em: <http://www.scielo.br/pdf/cagro/v27n2/a27v27n2.pdf>

SANTOS, A. N.; SOARES, T. M.; SILVA, E. F. F.; SILVA, D. J. R.; MONTENEGRO, A. A. A. Cultivo hidropônico de alface com água salobra subterrânea e rejeito da dessalinização em Ibimirim, PE. Revista Brasileira de Engenharia Agrícola e Ambiental, v.14, n.9, p.961-969, 2010. Disponível em: <http://dx.doi.org/10.1590/S1415-43662010000900008> DOI: 10.1590/S141543662010000900008

SCHERER, K.; GRANADA, C. E.; STULP, S.; SPEROTTO, R. A. Avaliação bacteriológica e físico-química de águas de irrigação, solo e alface (Lactuca sativa L.). Revista Ambiente \& Água, v. 11 n. 3 Taubaté - Jul. / Set. 2016. Disponível em: < http://dx.doi.org/10.4136/ambi-agua.1829> DOI: 10.4136/ambi-agua.1829

TAIZ, L.; ZEIGER, E. Plant physiology. 3.ed. Porto Alegre: Artmed, 2009. 719p.

TESTER, M.; DAVENPORT, R. $\mathrm{Na}^{+}$tolerance and $\mathrm{Na}^{+}$transport in higher plants. Annals of Botany, v.91, p.503-527, 2003. Disponível em: <http://dx.doi. org/10.1093/aob/mcg058> DOI: $10.1093 / \mathrm{aob} / \mathrm{mcg} 058$. 